\title{
The Significance of Study on Dialects Contact in Zhan-Mao Area in West Guangdong of China
}

\author{
Jianya Zhang \\ College of Liberal Arts \\ South China Normal University \\ Guangzhou, China 510006
}

\author{
Weiming Peng \\ College of Liberal Arts \\ South China Normal University \\ Guangzhou, China 510006
}

\begin{abstract}
As two local central cities, Zhanjiang and Maoming are in the west of Guangdong, wherethere are various and different dialects, mainly including Cantonese, Min dialect and Hakka. And in many areas there people communicate in bidialects or multi-dialects in a mixed way, typically representing the local dialects contact situation.
\end{abstract}

Keywords-China; West Guangdong; dialects contact; exemplary; significance

\section{INTRODUCTION}

West Guangdong mainly consists of four prefectural-level cities: Zhanjiang, Maoming, Yangjiang and Yunfu, in which, Zhanjiang and Maoming are taken as regional central cities and called Zhan-Mao Area for short. Zhanjiang is located at the most south part of mainland China, the southwest Guangdong where it connects the Guangdong, Guangxi and Hainan Provinces, and covers the entire Leizhou Peninsula and a part at the north of the Peninsula, with east to the South China Sea, south to Hainan Province over the Qiongzhou Strait, west to the North Bay, northwest to Guangxi Province and northeast to Maoming City. At present, there are 4 municipal districts (Chikan, Xiashan, Potou and Mazhang) and 5 county-level cities (Lianjiang, Wuchuan, Suixi, Leizhou and Xuwen). While, Maoming is located at the southwest of Guangdong, with west to Zhanjiang, north to Yunfu, south to South China Sea, where there are 2 municipal districts (Maonan District and Dianbai District) and 5 county-level cities (Gaozhou, Xinyi and Huazhou).

\section{APPLICATION OF DIALECTS IN ZHAN-MAO AREA IN WEST GUANGDONG OF CHINA}

There are a large number of dialects existing in west Guangdong, because where there are Guangdong people, Fujian people and Hakka people three ethnic groups live, mainly including Cantonese, Min and Hakka, etc. Cantonese, commonly known as "Baihua dialect" in west Guangdong, is divided into Gaoyang District, Wuhua District and Luoguang District. Influenced by Cantonese, it has the same dominant position in west Guangdong; Min in west Guangdong, also known as Leizhou dialect or Li dialect, is mainly distributed in Leizhou in south Zhanjiang and Dianbai of Maoming, etc.; Hakka in west Guangdong, also known as $\mathrm{Ai}$ dialect, is mainly distributed in Lianjiang in northwest Zhanjiang, Gaozhou, Xinyi and Dianbai of Maoming, Luoding and
Xinxing of Yunfu as well as Yangchun of Yangjiang, etc. This article describes the application situation of dialects in Zhanjiang and Maoming Areas.

Current dialects applied within Zhanjiang mainly include Cantonese, Leizhou dialect, Hakka and Hai dialect. Firstly, Cantonese, as the dialect most widely distributed and most people use, is mainly applied in Wuchuan County and Zhanjiang downtown area as well as the county-level city Lianjiang downtown area. Cantonese in Zhanjiang is similar to Guangzhou. Secondly, Leizhou dialect, as one of Fujian dialects, commonly known as "Lei dialect" or "Li dialect" by local people in Haikang. Thirdly, Hakka, also called the Ai dialect by local people, is mainly applied in the mountainous area in the northern part of Lianjiang City. The Hakka of the Leizhou Peninsula is similar to which of the old Jiayingzhou area in the eastern part of Guangdong. Fourthly, the Hai dialect, mainly used in Lianjiang coastal area, belongs to Cantonese family, with characteristics similar to the Cantonese of Liancheng Town, mainly including Cheban, Gaoqiao and Yingzai areas at Lianjiang coastal.[1]

The main dialects of Maoming City is not very different from Zhanjiang, including Cantonese, Hakka, Lei dialect and Hai dialect, except for the Hai dialect of Maoming being Min, similar to Leizhou dialect, which is mainly used in Diancheng, Bohe, Shayuan and Nanhai at Dianbai County coastal. Dialects are distributed closely based on their natural environment. Firstly, Maoming Cantonese, as the dialect most widely distributed and most people use, is the native dialect of about 3.2 million people, accounting for $65 \%$ of the general population of the city, which is applicable over the whole city. The Cantonese speakers are mainly living at coastal Jianjiang and its branches: Luojiang, Lingjiang and Caojiang, etc. Secondly, Hakka, applied by about 1 million people in Maoming, accounting for $20 \%$ of the general population of the city, is distributed in the border mountains areas in east, west and northeast areas. Thirdly, Lei dialect, applied by about 0.55 million people in Maoming, accounting for $10 \%$ of the general population while Hai dialect, in the Min family same to Lei dialect, is applied by about 0.3 million people. People who speak Lei dialect and Hai dialect are mainly distributed in east and south coastal areas. In addition to the foresaid dialects, there are "Jiushizheng" dialect, Sihe dialect and Rong County dialect applied in Maoming, which accounts for about $5 \%$ of the total population. 


\section{RESEARCH ON DIALECTS HYBRIDIZATION}

In west Guangdong of China, there are rich dialect resources that Cantonese, Hakka and Min the three main dialects coexist, impact each other and are applied in a hybrid way. Even the dialect border and relatively developed town have become bilingual or multilingual area where people are able to speak several dialects. Taking Lianjiang, a countylevel city governed by Zhanjiang city from Zhanjiang and Maoming as sample, we carefully research the dialect hybridization practices in the sample area, including:

\section{A. Subject, Object and Method of Investigation}

This article investigates the whole streets ( 3 streets) and town-level districts (18 districts) by form of questionnaire on their population resources and dialect applications. In order to ensure the accuracy of the investigation subject, we investigate the governmental staff of towns in Lianjiang City by questionnaire and, for several local residents, individual visit form.

\section{B. Material Resource}

All the materials obtained in this investigation come from the town governments and street administration offices in Lianjiang. The investigation started on September 2013 and supplemented on December 2017.

\section{Questionnaire}

The following questions are set in the questionnaire:

(1) What is the total population of the town? (of household population; as of 2012)
(2) How many people in this town go out as migrant workers all year round? Where do they go?

(3) How many people are the permanent migrant residents in this town? Which provinces or adjacent provinces are mainly from?

(4) What is the main dialect of the town? What's the ratio?

(5) Is there a second or third dialect?

(6) Can the main dialect speakers understand the second or third dialect? Can you speak a second or third dialect? Can the second or third dialect speakers speak the main dialect?

\section{Findings}

For limited space, all questionnaires on the abovementioned questions cannot be listed, and the findings are as follows:

The total population of Lianjiang City is about 165,000 , less people in Jishui, Liangdong, Shicheng go out for work, while the other towns have more than 10,000 or ten thousands of people go out of work. The work destination of each town or street is basically the economically developed Pearl River Delta area. There are also very few people migrated in each town, mostly because of marriage, mainly from Guangxi, Guizhou, Hunan, Sichuan, Hainan, Fujian and other neighboring provinces. The findings of the specific usage of the dialect are presented in forms, summing up the towns with same first dialectin a table, three tables in total: the "Table I" refers to towns and streets with Cantonese as first dialect; the "Table II" refers to towns with Min as first dialect; the "Table III" refers to towns with Hakka as first dialect.

TABle I. Dialect Application Situation1 of Towns with Cantonese As First Dialect ${ }^{1}$ (Population Unit: Ten Thousand)

\begin{tabular}{|l|l|l|l|l|l|l|l|l|l|}
\hline Street/Town & $\begin{array}{c}\text { General } \\
\text { Population }\end{array}$ & $\begin{array}{c}\text { Number } \\
\text { of People } \\
\text { Go Out } \\
\text { for } \\
\text { Work }\end{array}$ & $\begin{array}{c}\text { Number } \\
\text { of } \\
\text { Migrant } \\
\text { Worker }\end{array}$ & $\begin{array}{c}\text { Cantonese } \\
\text { Speaker } \\
\text { Ratio }\end{array}$ & $\begin{array}{c}\text { Other } \\
\text { Dialects }\end{array}$ & $\begin{array}{c}\text { Understand } \\
\text { and Speak } \\
\text { Min or Not }\end{array}$ & $\begin{array}{c}\text { Understand } \\
\text { and Speak } \\
\text { Hakka or } \\
\text { Not }\end{array}$ & $\begin{array}{c}\text { Whether Min } \\
\text { Speakers Can } \\
\text { Understand and } \\
\text { Speak Cantonese } \\
\text { or Not }\end{array}$ & $\begin{array}{c}\text { Whether Hakka } \\
\text { Speakers Can } \\
\text { Understand and } \\
\text { Speak } \\
\text { Cantonese or } \\
\text { Not }\end{array}$ \\
\hline Luozhou & 11.3 & 3.26 & 3.8 & $79 \%$ & $\mathrm{Ha} / \mathrm{Mi}$ & - & - & ++ & ++ \\
\hline Chengnan & 3.2 & 0.2 & 0.7 & $95 \%$ & $\mathrm{Ha}$ & $/$ & + & $/$ & ++ \\
\hline Chengbei & 3.4 & 0.42 & 0.02 & $96 \%$ & $\mathrm{Ha} / \mathrm{Mi}$ & - & ++ & ++ & ++ \\
\hline Anpu & 13.02 & 3.5 & 0.5 & $76.8 \%$ & $\mathrm{Mi} / \mathrm{Ha}$ & $\Delta$ & + & ++ & ++ \\
\hline Cheban & 5.1 & 2.19 & 0.022 & $70 \%$ & $\mathrm{Mi} / \mathrm{Ha}$ & ++ & - & ++ & ++ \\
\hline Jishui & 7.68 & 0.2 & 0.03 & $52 \%$ & $\mathrm{Ha}$ & $/$ & ++ & $/$ & + \\
\hline Shicheng & 7.4 & 0.18 & 0.01 & $99 \%$ & $\mathrm{Mi} / \mathrm{Ha}$ & $\Delta$ & + & + & ++ \\
\hline Xinmin & 5.76 & 0.9 & 0.01 & $69 \%$ & $\mathrm{Mi}$ & + & $/$ & ++ & + \\
\hline Yingzai & 10.5 & 3.12 & 0.27 & $42 \%$ & $\mathrm{Mi} / \mathrm{Ha}$ & + & ++ & + \\
\hline Gaoqiao & 3.58 & 1.15 & 0.023 & $60 \%$ & $\mathrm{Ha} / \mathrm{Li}$ & - & + & + & + \\
\hline
\end{tabular}

One "+"refers to people who can understand but not speak, two "+"refers to people who can understand and speak, "-"refers to people who can neither understand nor speak. " $\Delta$ "refers to few people who can understand and speak, "/refers to not applicable. 
From the above table, there are 10 towns with Cantonese as first dialect in Lianjiang where most Cantonese speakers have strong ability to understand and speak Hakka or Min and more people speak Hakka than Min; some Min and Hakka speakers can largely understand and speak Cantonese.

TABle II. Diflect Application Situation1 of Towns with Min As First Dialect (Population Unit: Ten Thousand)

\begin{tabular}{|c|c|c|c|c|c|c|c|c|c|}
\hline Street/Town & $\begin{array}{c}\text { General } \\
\text { Population }\end{array}$ & $\begin{array}{c}\text { Number of } \\
\text { People Go } \\
\text { Out for } \\
\text { Work }\end{array}$ & $\begin{array}{c}\text { Number of } \\
\text { Migrant } \\
\text { Worker }\end{array}$ & $\begin{array}{c}\text { Min } \\
\text { Speaker } \\
\text { Ratio }\end{array}$ & $\begin{array}{c}\text { Other } \\
\text { Dialects }\end{array}$ & $\begin{array}{c}\text { Understand } \\
\text { and Speak } \\
\text { Cantonese } \\
\text { or Not }\end{array}$ & $\begin{array}{c}\text { Understand } \\
\text { and Speak } \\
\text { Hakka or } \\
\text { Not }\end{array}$ & $\begin{array}{c}\text { Whether } \\
\text { Cantonese } \\
\text { Speakers Can } \\
\text { Understand and } \\
\text { Speak Min or } \\
\text { Not }\end{array}$ & $\begin{array}{l}\text { Whether Hakka } \\
\text { Speakers Can } \\
\text { Understand and } \\
\text { Speak Min or } \\
\text { Not }\end{array}$ \\
\hline Hengshan & 13.4 & 3.5 & 0.03 & $90 \%$ & $\mathrm{Ca} / \mathrm{Ha}$ & ++ & - & + & - \\
\hline Liangdong & 12.68 & 0.64 & 0.028 & $81 \%$ & $\mathrm{Ca}$ & ++ & - & + & - \\
\hline
\end{tabular}

There are 2 towns with Min as first dialect in Lianjiang where the Min speakers can largely understand and speak Cantonese but not Hakka; part Cantonese speakers can

understand Min but not speak; few Hakka speakers cannot understand or speak Min.

TABLE III. Dialect Application Situation1 of Towns with Hakka As First Dialect (Population Unit: Ten Thousand)

\begin{tabular}{|c|c|c|c|c|c|c|c|c|c|}
\hline Street/Town & $\begin{array}{c}\text { General } \\
\text { Population }\end{array}$ & $\begin{array}{c}\text { Number } \\
\text { of } \\
\text { People } \\
\text { Go Out } \\
\text { for } \\
\text { Work }\end{array}$ & $\begin{array}{l}\begin{array}{c}\text { Number } \\
\text { of } \\
\text { Migrant } \\
\text { Worker }\end{array} \\
\end{array}$ & $\begin{array}{c}\text { Hakka } \\
\text { Speaker } \\
\text { Ratio }\end{array}$ & $\begin{array}{l}\text { Other } \\
\text { Dialects }\end{array}$ & $\begin{array}{c}\text { Understand } \\
\text { and Speak } \\
\text { Cantonese } \\
\text { or Not }\end{array}$ & $\begin{array}{l}\text { Understand } \\
\text { and Speak } \\
\text { Min or Not }\end{array}$ & $\begin{array}{c}\text { Whether } \\
\text { Cantonese } \\
\text { Speakers } \\
\text { Can } \\
\text { Understand } \\
\text { and Speak } \\
\text { Hakka or } \\
\text { Not } \\
\end{array}$ & $\begin{array}{c}\text { Whether } \\
\text { Min } \\
\text { Speakers } \\
\text { Can } \\
\text { Understand } \\
\text { and Speak } \\
\text { Hakka or } \\
\text { Not } \\
\end{array}$ \\
\hline Heliao & 5.329 & 1.85 & 0.042 & $96 \%$ & $\mathrm{Ca}$ & ++ & - & + & + \\
\hline Hechun & 8.3 & 1.8 & 0.4 & $98 \%$ & $\mathrm{Ca} / \mathrm{Mi}$ & ++ & - & + & + \\
\hline Qingping & 9.99 & 4 & 0.2 & $70 \%$ & $\mathrm{Ca} / \mathrm{Mi}$ & ++ & + & + & + \\
\hline Shijiao & 6.51 & 1.95 & 0.065 & $99.9 \%$ & $\mathrm{Ca} / \mathrm{Mi}$ & ++ & + & + & - \\
\hline Shijing & 5.4 & 2.1 & 0.09 & $99.9 \%$ & $\mathrm{Ca}$ & + & I & - & 1 \\
\hline Shiling & 11.7 & 3.76 & 0.13 & $65 \%$ & $\mathrm{Ca} / \mathrm{Mi}$ & ++ & $\Delta$ & + & ++ \\
\hline Tangpeng & 8.97 & 4.85 & 0.08 & $95 \%$ & $\mathrm{Ca}$ & ++ & 1 & $+\Delta$ & 1 \\
\hline Yatang & 5 & 1 & 0.01 & $95 \%$ & $\mathrm{Ca} / \mathrm{Mi}$ & ++ & - & + & + \\
\hline Changshan & 6.86 & 2.65 & 0.046 & $95 \%$ & $\mathrm{Ca} / \mathrm{Mi}$ & ++ & $\Delta$ & + & - \\
\hline
\end{tabular}

There are 9 towns with Hakka as first dialect in Lianjiang where Hakka speakers can largely understand and speak Cantonese while few of them can understand Min; most Cantonese and Min speakers can understand Hakka but few of them can speak.

In conclusion, we can have the following information: 1 . Cantonese and Hakka speaking towns are in the majority while fewer towns speak Min, and Cantonese and Hakka speakers are much more than Min speakers; 2. Min and Hakka speakers can largely understand Cantonese, and most of which can speak Cantonese, and they have stronger ability to understand and speak Cantonese than other dialects; 3 . There are 10 Cantonese speaking towns and 9 Hakka speaking towns that the number of Cantonese and Hakka speakers is similar, but the applying degree of Cantonese is obviously more current than Hakka; 4. Min and Hakka speakers are not good to understand or speak the dialects of each other that some Hakka speakers can understand Min but few Min speakers can understand Hakka. Lianjiang area has rich and various Chinese dialects where the dialect areas closely neighbor each other that it is very easy to form bilingual situation in daily communication. Hence, different dialects are further interacted with the time goes by. Throughout the application situation of dialects in Zhanjiang and Maoming areas, the Cantonese speaking area is with better economy and culture, so that it not only becomes the communicating tool of
Cantonese speaker group but also becomes their status symbol which gives the Cantonese speakers strong sense of language pride and internal identity, while Min and Hakka areas, which are in relatively weak status, gradually popularize Cantonese for communication.

\section{SignifiCANCE OF RESEARCH ON DiALECTS CONTACT IN WEST GUANGDONG}

\section{A. Cantonese, Hakka and Min Contacts in Zhanjiang and Maoming Areas Are of Strong Typicality and Demonstration}

Different dialect contacts in Guangdong are mostly bilingual, such as Cantonese-Hakka (Zengcheng and Siyi, taishan of Guangzhou, etc.), Hakka-Min (Jiexi and Raoping, etc.) and Cantonese-Min (Yangjiang and Zhanjiang, etc.) where it is not common that three dialects closely coexist in one area for a long time. According to our investigation, the dialect types in Zhanjiang and Maoming areas are very rich and various. The multi-dialects mixed language background that most towns and cities regard Cantonese, Min and Hakka as dominant dialects is a treasure of great value for research on Chinese dialects. It is unavoidable that different dialects interact with different dialect speakers living together. It is impossible to research pure single dialect in such background but to take full advantage of current complicated language 
background to investigate them in combination with their contact relationship with surrounding dialects. The theory of dialect contact is established on the basis of theory of language contact, while due to difference of the research object, the practice of theories does not go well. More materials are demanded to make breakthrough of the theory of dialect contact, and with the description and analysis of dialect contact facts, it can better form the theory of Chinese dialects.

\section{B. Inevitability of the Research Subject Transiting to Similarity Digging from Embodying Their Difference}

The previous researches on dialects in west Guangdong are mainly limited to internal research of individual dialect or comparative research among different dialects with findings concerning their differences. The researches on differences among dialects give us assistance to recognize the characteristics of different dialects, however, it make us easier to neglect their similarity. Although the separate researches on Cantonese, Hakka and Min in west Guangdong have made great progress, but research on the contact relationship among them is relatively weak, or in the beginning stage you can say. The Cantonese, Hakka and Min speakers are roughly regarded having been migrated from east Guangdong, north Guangdong, middle Guangdong and south Fujian, etc. in the twentieth century, about nearly one hundred or over one hundred year ago. The quantity of speakers have stably increased in the long development process, in addition, it has a long history of dialect contact and is of great influence, which is a relatively typical case in researches on Chinese dialects contact. At present, most researches on dialect contact in west Guangdong involve in few voice, vocabulary and grammar items and no systematical or wide contact research has been made, hence, we select the field as research object, detail the typical language fact point for comprehensive comparison and deep analysis and focus on the common characteristics of dialects under the influence of contact, so as to differ from the researches on difference among dialects. We mainly discuss on the contact mechanism, type and characteristics of vocabulary borrowing, changes of vocabulary meanings and structure under the influence of contact as well as their changing trends in the future.

\section{The Borrowing of Language, Even the Dialect, Is the Issue of Language Contact Research and Historical Linguistics}

If one person uses two or more than two languages, we can say these two languages are in contact. Weinreich calls people who use two languages the "bilingual" and regards the deviation from language standard as language interference. He thinks that vocabulary is easier to be the central field [3] of borrowing due to fact that the vocabulary of language is not as rigorous as the phoneme and grammar. Haugen's definition of borrowing can be concluded as: the speaker learns the part of another language and creates a new pattern based on his own language mode, while such new pattern does not exist or is the different part [4] in his own language. Borrowing is spread or diffusion to the source language but acceptance or absorption to the target language, and the accumulation of different borrowed language systems as well as the heterogeneous compositions generated from language contact can separate out systematical levels through organization. Language levels, different from the superposed level of objects, are in the synchronic plane of language. As the product of language contact, the language level can separate out the levels mixed on synchronic planes in historic order by diachronic strata analysis method. The simple lineage theory has not met the practical evolution analysis of language anymore; hence, it is unavoidable to further research on the historical mechanism and operating mechanism of language contact. The research on the complicated hierarchy of language contact is inseparable from the discussion on language homology; hence, stripping the borrowing compositions of language and the research on language contact is the issue of historical linguistics as well.

\section{CONCLUSION}

The Cantonese, Hakka and Min dialects in west Guangdong coexist and interact, which involve in dialect contact in aspects of voice, vocabulary and grammar; however, the research on dialects in west Guangdong is traditionally weaker than the Cantonese of the Pearl River Delta, Min of Chaoshan as well as the Hakka of Meizhou. It is of great theoretical and practical significance for construction of dialect contact theory to investigate the contact and evolution of dialects in Zhanjiang and Maoming areas.

\section{REFERENCES}

[1] Compiled by Zhanjiang Municipal Committee for Local Gazettee Compilation. Zhanjiang Municipal Gazetteer (1979-2000) [M] Guangzhou: Guangdong People Publishing House, 2013:908-909. 湛江 市地方志编纂委员会编.湛江市志（1979-2000）[M].广州: 广东人 民出版社，2013:908-909.

[2] Compiled by Maoming Municipal Committee for Local Gazetteer Compilation. Maoming Municipal Gazetteer (1979-2000) [M] Guangzhou: Lingnan Fine Arts Publishing House, 2014:1594-1595. 茂 名市地方志编纂委员会编.茂名市志（1979-2000）[M].广州：岭南 美术出版社，2014:1594-1595.

[3] (USA) UrielWeinreich, Languages in Contact: Findings and Problems, Mouton Publishers, The Hugue, 1968, pp.7-106.

[4] (USA) Einar Haugen, "The Analysis of Linguistic Borrowing", Language, Vol.26, No.2, 1950, pp.210-231. 